\title{
Mortality following primary total knee replacement in public hospitals in Hong Kong
}

\author{
QJ Lee *, WP Mak, YC Wong
}

\section{A B S T R A C T}

Introduction: More than 2000 total knee replacements are performed each year in Hong Kong and more than 10000 patients are on the waiting list. How safe is total knee replacement, however? The aims of the study were to review the mortality of primary total knee replacement in public hospitals in Hong Kong and to identify risk factors for mortality in a high-volume hospital.

Methods: All primary total knee replacements performed in Hospital Authority hospitals and Yan Chai Hospital from October 2011 to September 2014 were reviewed. Case-control analysis was performed for risk factors of total all-cause mortality in total knee replacement at Yan Chai Hospital.

Results: There were 6588 patients in Hospital Authority hospitals and 1184 in Yan Chai Hospital (1095 unilateral and 89 bilateral total knee replacement). The mean follow-up time of patients in Yan Chai Hospital was 12.8 months. The mortality at 30 days, 90 days and 1 year was $0 \%, 0.08 \%, 0.34 \%$ for Yan Chai Hospital; and 0.1\%, 0.2\%, 0.7\% for Hospital Authority hospitals, respectively. For Yan Chai Hospital, the mean operation-to-death interval was 21 months (range, 1-35 months). The mean age at
This article was published on 6 May 2016 at www.hkmj.org. included age at surgery, American Society of Anesthesiologists class 3, and preoperative range of motion. Hospital surgery volume, preoperative comorbidities, and postoperative deep vein thrombosis were not significant factors.

Conclusions: Mortality after primary total knee replacement was low in public hospitals in Hong Kong. Patients of older age or poorer general wellbeing in terms of poor range of motion or American Society of Anesthesiologists class 3 should be in optimal health before surgery and counselled about the higher mortality rate. A citywide joint replacement registry may help monitor and analyse postoperative total knee replacement mortality specific to our locality.

\section{Hong Kong Med J 2016;22:237-41}

DOI: 10.12809/hkmj154712

QJ Lee *, FHKCOS, FHKAM (Orthopaedic Surgery)

WP Mak, MPHC, FPHKAN

YC Wong, FHKCOS, FHKAM (Orthopaedic Surgery)

Joint Replacement Centre, Yan Chai Hospital, Tsuen Wan, Hong Kong

* Corresponding author: leejasper@gmail.com

New knowledge added by this study

Preoperative range of motion may be predictive of mortality in primary total knee replacement.

Implications for clinical practice or policy

- Proper preoperative optimisation of general health and counselling is necessary before primary total knee replacement.

\section{Introduction}

More than 2000 primary total knee replacements (TKR) are performed in Hong Kong each year and more than 10000 patients are on the waiting list for TKR at public hospitals. With an ever-increasing waiting list, joint replacement centres with high surgery volume have been set up in public hospitals. More such centres are planned in the future to tackle the ageing population and rising demand. As one of the most popular elective 'ultra-major' surgeries, how safe is primary TKR?

According to various knee replacement registries, 30-day mortality of TKR ranges from
$0.2 \%$ to $0.4 \%$, 90 -day mortality $0.4 \%$ to $0.7 \%$, and 1 -year mortality $1 \%$ to $2 \%^{1-8}$ Risk factors for postTKR mortality include age at operation, male sex, too high or low body mass index, American Society of Anesthesiologists (ASA) class 3 to 4, presence of co-morbidities, and simultaneous bilateral surgery. ${ }^{1-4,6-12}$ There are a lack of similar data for the Asian population, however, and the risk of mortality in a high-volume hospital has not been described locally. The aims of the study were to review the mortality of primary TKR in Hong Kong and to identify risk factors of post-TKR mortality in a highvolume hospital. 


\section{香港公立醫院初次全膝關節置換術後的死亡率}

\section{李君哲、麥惠萍、黃耀忠}

引言：香港每年有超過2000個全膝關節置換術, 且超過 10000 名患者 在候診。然而, 全膝關節置換術是否安全? 本研究旨在審查在香港公 立醫院初次全膝關節置換術後的死亡率, 並找出在一所高手術量醫院 中初次全膝關節置換術後死亡的危險因素。

方法：回顧分析於2011年10月至2014年9月期間所有在香港公立醫院 和仁濟醫院接受初次全膝關節置換術的患者, 並進一步利用病例對照 研究分析仁濟醫院內初次全膝關節置換術的總全因死亡的危險因素。

結果：研究期間香港公立醫院共有6588名患者, 仁濟醫院則有 1184 名患者（其中1095例屬單邊置換術，89例屬雙邊置換術）。仁濟醫院 患者的平均跟進期為 12.8 個月，其 30 天、 90 天和 1 年死亡率分別為 $0 \%$ 、 $0.08 \%$ 和 $0.34 \%$, 香港公立醫院的則依次為 $0.1 \% 、 0.2 \%$ 和 $0.7 \%$ 。仁 濟醫院患者的平均死亡時間為術後 21 個月（介乎1-35個月）, 平均死 亡年齡為78歲, 主要原因是惡性腫瘤（50\%），其次為肺炎（21\%）

。死亡率的預測因素包括手術年齡、ASA 3級和術前關節活動度。醫 院手術量、術前合併症和術後下肢深靜脈血栓均不是預測因素。

結論：香港公立醫院初次全膝關節置換術後的死亡率低。年齡較大或 整體健康較差的患者（即關節活動度不佳或屬ASA 3 級），醫生須確 定病人術前的健康狀況良好才建議他們接受手術; 病人亦應於術前理 解此手術有較高死亡率。全民關節置換註冊表有助監測和分析初次全 膝關節置換的術後死亡率。

\section{Methods}

\section{Data retrieval}

All primary TKR performed in public hospitals (Hospital Authority) and all primary TKR at the authors' institute (Yan Chai Hospital, YCH) from October 2011 to September 2014 were reviewed. Data retrieval for all public hospitals was performed with the Clinical Data Analysis and Reporting System. Procedure code for retrieval was "81.54 TOTAL KNEE REPLACEMENT". Data of patients at our institute were retrieved additionally with Clinical Management System of the Hospital Authority. The medical records of all deceased cases before September 2015 were reviewed.

\section{Data analyses}

The primary outcome measures were 30-day, 90-day, and 1-year mortality. Correlation coefficient between 30-day, 90-day, and 1-year mortality and annual surgery volume of all public hospitals was calculated with Pearson test. From data of $\mathrm{YCH}$, comparisons were made between the mortality of unilateral TKR and simultaneous bilateral TKR. Case-control analysis was performed for possible risk factors of primary TKR total mortality. A control group included non-mortality cases of all simultaneous bilateral TKR in the same period and all unilateral primary TKR performed from October
2012 to March 2013. The latter period was chosen to allow a 1-year 'run-in' time for the newly established joint replacement centre that commenced operation in October 2011. All bilateral cases were used due to their relative scarcity. Chi squared test and Fisher's exact test were used for univariate analysis, and multiple logistic regression was used for multivariate analysis. Final model for multiple logistic regression was identified by backward elimination. A P value of $<0.05$ was considered statistically significant.

\section{Results}

There were 6588 primary TKR in 15 public hospitals and 1184 primary TKR at YCH (1095 unilateral and 89 bilateral). The 30-day, 90-day, and 1-year mortality was $0 \%(n=0), 0.08 \%(n=1)$, and $0.34 \%(n=4)$ for $\mathrm{YCH}$ and $0.1 \%(n=8), 0.2 \%(n=16)$, and $0.7 \%(n=48)$ for all public hospitals (YCH inclusive), respectively (Table 1). There was no correlation between hospital surgery volume and 30-day, 90-day, or 1-year mortality among the 15 public hospitals $(R=0.151, \mathrm{P}=0.578$; $R=0.031, \mathrm{P}=0.910 ; R=0.032, \mathrm{P}=0.972$, respectively). For cases at $\mathrm{YCH}$, the mean follow-up time was 12.8 (range, 4-38) months, the mean operation-todeath interval was 21 (1-35) months, and the mean age at death was 78 (70-87) years. Main causes of death were malignancy (50\%) and pneumonia (21\%) [Table 2]. Significant predictors of total mortality identified by univariate analysis included age at operation, preoperative range of motion (ROM), and ASA class 3; the former two were also confirmed by the final model of multivariable analysis (Table 3 ). The mean age at operation was 76 versus 68 years for mortality and non-mortality cases while the mean preoperative ROM was 95 versus 108 degrees, respectively. Body mass index, co-morbidities, deep vein thrombosis (DVT) prophylaxis, and postoperative DVT did not differ significantly between the two groups. Preoperative Western Ontario and McMaster Universities Arthritis Index (WOMAC), Knee Society score (KSS), and function score (FS) were also not significantly different. There was no significant difference in 30-day, 90-day, or 1 -year mortality for bilateral TKR versus unilateral TKR (Table 1).

\section{Discussion}

\section{Mortality rate}

The 30-day, 90-day, and 1-year mortality in Hong Kong public hospitals was $0.1 \%, 0.2 \%$, and $0.7 \%$, respectively. These compared favourably with data of large national joint registries of other countries: $0.2 \%$ to $0.4 \%, 0.4 \%$ to $0.7 \%$, and $1 \%$ to $2 \%$, respectively. ${ }^{1-8}$ There is no definitive explanation for such findings but several possibilities exist. First, TKR is still mostly considered a 'risky' and major operation in Hong Kong such that the popularity of such surgery 
TABLE I. Comparison of mortality rates

\begin{tabular}{|c|c|c|c|c|c|c|}
\hline \multirow[t]{2}{*}{ Mortality } & \multicolumn{3}{|c|}{ YCH $(n=1184)$} & \multirow[t]{2}{*}{$\begin{array}{l}\text { HA, 2011-2014 } \\
(n=6588)\end{array}$} & \multicolumn{2}{|c|}{$\begin{array}{l}\text { HK general population age-specific } \\
\text { annual all-cause mortality rate at } 2013^{16}\end{array}$} \\
\hline & $\begin{array}{l}\text { Bilateral TKR } \\
(n=89)\end{array}$ & $\begin{array}{l}\text { Unilateral TKR } \\
(n=1095)\end{array}$ & Total & & Age 65-69 years & Age $70-74$ years \\
\hline 30-Day & $0 \%(n=0)$ & $0 \%(n=0)$ & $0 \%(n=0)$ & $0.1 \%(n=8)$ & $0.92 \%$ & $1.65 \%$ \\
\hline 90-Day & $0 \%(n=0)$ & $0.09 \%(n=1)$ & $0.08 \%(n=1)$ & $0.2 \%(n=16)$ & & \\
\hline 1-Year & $0 \%(n=0)$ & $0.37 \%(n=4)$ & $0.34 \%(n=4)$ & $0.7 \%(n=48)$ & & \\
\hline
\end{tabular}

Abbreviations: $\mathrm{HA}=$ Hospital Authority; $\mathrm{HK}=$ Hong Kong; TKR = total knee replacements; $Y C H=$ Yan Chai Hospital

TABLE 2. Summary of mortality cases in Yan Chai Hospital from October 2011 to September 2014

\begin{tabular}{lcccccccl}
\hline $\begin{array}{l}\text { Case } \\
\text { No. }\end{array}$ & Surgery & Sex & $\begin{array}{c}\text { ASA } \\
\text { class }\end{array}$ & $\begin{array}{c}\text { Pre-ROM } \\
\text { (degrees) }\end{array}$ & $\begin{array}{c}\text { Age at surgery } \\
\text { (years) }\end{array}$ & $\begin{array}{c}\text { Age at death } \\
\text { (years) }\end{array}$ & $\begin{array}{c}\text { Operation-to- } \\
\text { death interval } \\
\text { (months) }\end{array}$ & Cause of death \\
\hline 1 & Unilateral TKR & Female & 3 & 80 & 75 & 77 & 28 & Pneumonia \\
\hline 2 & Unilateral TKR & Female & 2 & 95 & 72 & 74 & 14 & Malignancy \\
\hline 3 & Unilateral TKR & Male & 1 & 95 & 75 & 75 & 10 & Aspiration \\
\hline 4 & Unilateral TKR & Female & 1 & 100 & 73 & 74 & 15 & Malignancy \\
\hline 5 & Unilateral TKR & Female & 2 & 80 & 75 & 79 & 35 & Dissecting aortic aneurysm \\
\hline 6 & Unilateral TKR & Male & 3 & 110 & 71 & 74 & 31 & Congestive heart failure, sepsis \\
\hline 7 & Unilateral TKR & Female & 3 & 100 & 68 & 70 & 17 & Malignancy \\
\hline 8 & Unilateral TKR & Female & 2 & 75 & 79 & 82 & 24 & Malignancy \\
\hline 9 & Unilateral TKR & Male & 3 & 105 & 85 & 87 & 31 & Malignancy \\
\hline 10 & Unilateral TKR & Female & 3 & 125 & 75 & 78 & 27 & Pneumonia \\
\hline 11 & Bilateral TKR & Male & 1 & 90 & 80 & 83 & 27 & Malignancy \\
\hline 12 & Unilateral TKR & Female & 3 & 90 & 81 & 81 & 3.5 & Pneumonia \\
\hline 13 & Unilateral TKR & Female & 2 & 65 & 81 & 81 & 1.2 & Possibly AMI / CVA, not determined \\
\hline 14 & Unilateral TKR & Female & 2 & 120 & 79 & 80 & 11 & Malignancy \\
\hline
\end{tabular}

Abbreviations: AMI = acute myocardial infarction; ASA = American Society of Anesthesiologists; CVA = cerebrovascular accident; Pre-ROM = preoperative range of motion; TKR = total knee replacement

remains low compared with other countries. In 2013, the incidence of primary TKR was around 4 per 10000 population in Hong Kong (estimated from data of the present study) compared with 12 in the United Kingdom, 14 in Sweden, and 19 in Australia. ${ }^{13-15}$ Lower operation incidence implies stricter selection criteria for operation. Second, the mortality of the general population of Hong Kong is known to be among the lowest in the world ${ }^{16}$; our findings may partly reflect the low mortality of the general population. Third, easy access to medical treatment in Hong Kong might facilitate timely intervention of early complications, hence reducing postoperative mortality. Whatever the explanation, the lower mortality indicates that primary TKR in Hong Kong are safe and conform to international standards.

One-year mortality following primary TKR in Hong Kong was lower than the mortality of the general population of the same age ${ }^{16}$ (Table 1). Similar findings have been shown by other studies. ${ }^{17}$ It has been suggested that strict selection criteria for operation meant that those selected were of better health than the general population. It was also hypothesised that pain relief and restored function would have a positive effect on a patient's overall health, hence a lower mortality in the long term. Nevertheless, 1-year may be too short a period for the latter effect to be obvious.

\section{Mortality risk factors}

In the present study, older age at operation was identified as a significant risk factor. This is consistent with findings in other studies. ${ }^{2-4,6-9,11,18}$ Some studies have reported higher $30-$ day, ${ }^{2-4}$ higher 90 -day, ${ }^{6,7}$ and even higher total mortality in the long term. ${ }^{9,11}$ With an ageing population and higher life expectancy, there will be more patients with older age in future who undergo TKR. To date, there is no consensus on an age limit for the procedure. It is agreed that patients in their 80s or even 90s could still benefit from the surgery ${ }^{18}$ provided the associated higher mortality is well explained and accepted.

The presence of co-morbidities was not a 
TABLE 3. Predictors of all-cause mortality in patients with primary total knee replacement in Yan Chai Hospital*

\begin{tabular}{|c|c|c|c|c|c|}
\hline & $\begin{array}{c}\text { All-cause mortality } \\
\text { cases }(n=14)\end{array}$ & Control $(n=279)$ & $\begin{array}{l}\text { P value (Chi squared / } \\
\text { Fisher's exact tests) }\end{array}$ & $\begin{array}{l}\mathrm{P} \text { value (multiple } \\
\text { logistic regression) }\end{array}$ & $\begin{array}{l}\text { Odds ratio } \\
(95 \% \mathrm{Cl})\end{array}$ \\
\hline Age (years) & $76 \pm 5$ & $68 \pm 8$ & $<0.001 \dagger$ & $0.057 / 0.01 \dagger$ & $1.10(1.00-1.22)$ \\
\hline Sex (female) & $71.4 \%$ & $68.1 \%$ & 1.000 & & \\
\hline BMI (kg/m²) & $27.5 \pm 2.5$ & $27.6 \pm 4.0$ & 0.951 & & \\
\hline Preoperative WOMAC & $46 \pm 16$ & $53 \pm 19$ & 0.308 & & \\
\hline Preoperative FS & $44 \pm 4$ & $46 \pm 11$ & 0.490 & & \\
\hline Preoperative KSS & $43 \pm 16$ & $51 \pm 14$ & 0.055 & & \\
\hline Preoperative ROM (degrees) & $95 \pm 17$ & $108 \pm 18$ & $0.007 \dagger$ & 0.005† / 0.001† & $0.92(0.87-0.98)$ \\
\hline Co-morbidities & $85.7 \%$ & $89.6 \%$ & 0.649 & & \\
\hline ASA class 3 & $38.9 \%$ & $19.3 \%$ & $0.047 \dagger$ & & \\
\hline Anaesthesia (SA) & $64.3 \%$ & $49.2 \%$ & 0.272 & & \\
\hline OT time (mins) & $97 \pm 11$ & $90 \pm 18$ & 0.180 & & \\
\hline DVT prophylaxis & $14.3 \%$ & $21.5 \%$ & 0.741 & & \\
\hline Postoperative DVT & $14.3 \%$ & $23.5 \%$ & 0.534 & & \\
\hline
\end{tabular}

Abbreviations: ASA = American Society of Anesthesiologists; BMI = body mass index; $\mathrm{Cl}=$ confidence interval; $\mathrm{DVT}=$ deep vein thrombosis; $\mathrm{FS}=$

function score; KSS = Knee Society score; OT = operating; ROM = range of motion; SA = spinal anaesthesia; WOMAC = Western Ontario and McMaster

Universities Arthritis Index

* Data are shown as mean \pm standard deviation or percentages, unless otherwise specified

$\dagger P$ value of the final model with backward analysis

significant predictor of mortality in the present study. Rather, the poor control or the severity of comorbidities in terms of ASA class 3 was found by univariate analysis to be a significant factor. There is evidence that patients with only specific comorbidities such as cardiovascular disease will have higher mortality. 1,4,6-8,19 In addition, higher 30-day mortality, ${ }^{3}$ 90-day mortality, ${ }^{6}$ and total mortality ${ }^{8,9}$ have been associated with higher ASA class. The lack of significance of ASA class 3 in multivariate analysis in our study suggests an underlying confounding factor. Analysis by $t$ test showed that the age of patients with ASA class 3 was significantly older (72 vs 67 years, $\mathrm{P}<0.001)$. Thus in the present study, ASA class was confounded by age at surgery.

Preoperative ROM was also found to be a significant factor by univariate and multivariate analyses in the present study. This might be a novel finding. The exact explanation for such an association requires exploration by further study. One possibility is that preoperative ROM predicts postoperative $\mathrm{ROM}^{20}$ that in turn affects postoperative ambulation and function. As mentioned above, it was hypothesised that restored ambulation and function can have a positive effect on a patient's overall health, hence a lower mortality. There are studies which reported an association between mortality and postoperative knee function. The latter was in terms of preoperative ambulatory status, ${ }^{8}$ postoperative ambulatory status, and postoperative WOMAC pain score. ${ }^{11}$ No knee score in the present study was found to be a significant predictor of mortality, however. One explanation could be that FS, WOMAC, and a large portion of
KSS are patient-reported outcomes whereas ROM is an objective measurement; the more objective the measurement, the better it might be in predicting a secondary outcome such as mortality.

Although bilateral TKR has been found by several studies to have a higher mortality rate, ${ }^{12,21,22}$ it was not a significant predictor in the present study. Our institute performed bilateral TKR in selected patients with mild and well-controlled co-morbidities and younger age. Also, the fast-track rehabilitation protocol was used with an average length of hospital stay of 9.6 days (authors' unpublished data). The results of analysis might reflect the equivalent safety of bilateral TKR with careful patient selection and fast-track rehabilitation. Many studies have demonstrated equal mortality for bilateral TKR with careful patient selection and a fast-track protocol. ${ }^{23,24}$

The present study has some limitations. First, due to inconsistent documentation across all public hospitals, data for case-control analysis for predictors of mortality were obtained from patients at our institute only. The smaller sample size limited the power of analysis of the present study. Second, since $70 \%$ of the mortality of our institute occurred more than 1 year after surgery and the mean operation-todeath interval was 21 months, analysis for predictors of mortality was performed on total mortality rather than 30-day, 90-day, or 1-year mortality. The very low early mortality in our institute and in Hong Kong means that a more powerful analysis of mortalities within 1 year may require a much larger sample size. This calls for a citywide joint replacement registry in which there is unified and detailed documentation of preoperative patient parameters, operative details, 
and postoperative outcome measurements. Such registries have already been established nationwide for 11 years in the United Kingdom ${ }^{13}$ and for 40 years in Sweden. ${ }^{14}$ Third, data for other known significant predictors of all-cause mortality, such as smoking and alcoholism, were not analysed. These factors might have confounded the present study. Since these factors are not known to be associated with age or preoperative ROM, the influence of these potential confounders on the conclusion of the present study should be insignificant. Lastly, the period chosen for selection of the control group did not fully match the death cases. This may have introduced confounding factors or made the groups incomparable. Since there was no change in the indications for surgery, surgical practice or rehabilitation protocol during the study period, and the sampled control should be representative of the target population.

\section{Conclusions}

Mortality after primary TKR was low in public hospitals in Hong Kong. Patients of older age or poorer general health in terms of poor ROM or ASA class 3 should be in optimal health before surgery and counselled about the higher mortality rate. The role of a pre-admission clinic and fast-track rehabilitation in contributing to the lower mortality in our institute should be further explored. A citywide joint replacement registry may help monitor and analyse post-TKR mortality specific to our locality.

\section{Declaration}

All authors have disclosed no conflicts of interest.

\section{References}

1. Hunt LP, Ben-Shlomo Y, Clark EM, et al. 45-Day mortality after 467,779 knee replacements for osteoarthritis from the National Joint Registry for England and Wales: an observational study. Lancet 2014;384:1429-36.

2. Lie SA, Pratt N, Ryan P, et al. Duration of the increase in early postoperative mortality after elective hip and knee replacement. J Bone Joint Surg Am 2010;92:58-63.

3. Belmont PJ Jr, Goodman GP, Waterman BR, Bader JO, Schoenfeld AJ. Thirty-day postoperative complications and mortality following total knee arthroplasty: incidence and risk factors among a national sample of 15,321 patients. J Bone Joint Surg Am 2014;96:20-6.

4. Parvizi J, Sullivan TA, Trousdale RT, Lewallen DG. Thirtyday mortality after total knee arthroplasty. J Bone Joint Surg Am 2001;83-A:1157-61.

5. Pedersen AB, Mehnert F, Sorensen HT, Emmeluth C, Overgaard S, Johnsen SP. The risk of venous thromboembolism, myocardial infarction, stroke, major bleeding and death in patients undergoing total hip and knee replacement: a 15-year retrospective cohort study of routine clinical practice. Bone Joint J 2014;96-B:479-85.

6. Singh JA, Lewallen DG. Ninety-day mortality in patients undergoing elective total hip or total knee arthroplasty. J Arthroplasty 2012;27:1417-1422.e1.
7. Gill GS, Mills D, Joshi AB. Mortality following primary total knee arthroplasty. J Bone Joint Surg Am 2003;85-A:432-5.

8. Jämsen E, Puolakka T, Eskelinen A, et al. Predictors of mortality following primary hip and knee replacement in the aged. A single-center analysis of 1,998 primary hip and knee replacements for primary osteoarthritis. Acta Orthop 2013;84:44-53.

9. Clement ND, Jenkins PJ, Brenkel IJ, Walmsley P. Predictors of mortality after total knee replacement: a ten-year survivorship analysis. J Bone Joint Surg Br 2012;94:200-4.

10. Thornqvist C, Gislason GH, Køber L, Jensen PF, TorpPedersen C, Andersson C. Body mass index and risk of perioperative cardiovascular adverse events and mortality in 34,744 Danish patients undergoing hip or knee replacement. Acta Orthop 2014;85:456-62.

11. Lizaur-Utrilla A, Gonzalez-Parreño S, Miralles-Muñoz FA, Lopez-Prats FA. Ten-year mortality risk predictors after primary total knee arthroplasty for osteoarthritis. Knee Surg Sports Traumatol Arthrosc 2015;23:1848-55.

12. Restrepo C, Parvizi J, Dietrich T, Einhorn TA. Safety of simultaneous bilateral total knee arthroplasty. A metaanalysis. J Bone Joint Surg Am 2007;89:1220-6.

13. 11th Annual Report. National Joint Registry for England, Wales and Northern Ireland. UK: National Joint Registry; 2014: 73-121.

14. Annual Report 2013. The Swedish Knee Arthroplasty Register; 2013: 2-55.

15. Australian Orthopaedic Association National Joint Replacement Registry. Annual Report. Adelaide: Australian Orthopaedic Association; 2014: 126-207.

16. The mortality trend in Hong Kong, 1981 to 2013. Hong Kong Monthly Digest of Statistics; 2014: 4-10.

17. Lovald ST, Ong KL, Lau EC, Schmier JK, Bozic KJ, Kurtz SM. Mortality, cost, and health outcomes of total knee arthroplasty in Medicare patients. J Arthroplasty 2013;28:449-54.

18. Miric A, Inacio MC, Kelly MP, Namba RS. Can total knee arthroplasty be safely performed among nonagenarians? An evaluation of morbidity and mortality within a total joint replacement registry. J Arthroplasty 2014;29:1635-8.

19. Robertsson O, Stefánsdóttir A, Lidgren L, Ranstam J. Increased long-term mortality in patients less than 55 years old who have undergone knee replacement for osteoarthritis: results from the Swedish Knee Arthroplasty Register. J Bone Joint Surg Br 2007;89:599-603.

20. Parsley BS, Engh GA, Dwyer KA. Preoperative flexion. Does it influence postoperative flexion after posteriorcruciate-retaining total knee arthroplasty? Clin Orthop Relat Res 1991;(275):204-10.

21. Hu J, Liu Y, Lv Z, Li X, Qin X, Fan W. Mortality and morbidity associated with simultaneous bilateral or staged bilateral total knee arthroplasty: a meta-analysis. Arch Orthop Trauma Surg 2011;131:1291-8.

22. Fu D, Li G, Chen K, Zeng H, Zhang X, Cai Z. Comparison of clinical outcome between simultaneous-bilateral and staged-bilateral total knee arthroplasty: a systematic review of retrospective studies. J Arthroplasty 2013;28:1141-7.

23. Kim YH, Choi YW, Kim JS. Simultaneous bilateral sequential total knee replacement is as safe as unilateral total knee replacement. J Bone Joint Surg Br 2009;91:64-8.

24. Powell RS, Pulido P, Tuason MS, Colwell CW Jr, Ezzet KA. Bilateral vs unilateral total knee arthroplasty: a patient-based comparison of pain levels and recovery of ambulatory skills. J Arthroplasty 2006;21:642-9. 